GORDON THOMAS GATLIN*

Yonsei University (Seúl, Corea)

\title{
La identidad bicultural en Malinche y Las dos orillas
}

Historical Bilingual Identity in Malinche and Las dos Orillas

A identidade bi cultural em Malinche e Las dos Orillas

\footnotetext{
* Candidato a maestría. Estudió historia y literatura de la época colonial de las américas en North Carolina State University y La Universidad del Salvador. Actualmente vive en Corea del Sur donde estudia la historia moderna de Corea, su economía e intercambio con las Américas. ORCID: oooo-0oo2-4239-1519. Correo electrónico: gtg297@gmail.com

** Este artículo surge de investigaciones del biculturalismo y bilingüismo en la época colonial de las Américas mientras estudiaba la enseñanza del español como lengua extranjera en la Universidad Nacional de Colombia en 2013. Artículo de investigación recibido el 22-01-2016 y aceptado 10-07-2017.
} 


\section{Cómo citar}

GATLIN, G. T. (2017). La identidad bicultural en Malinche y Las dos orillas. Revista CS, 23, 19-35.

DOI: http://dx.doi.org/10.18046/recs.i23.2124 
Este artículo analiza cómo los autores de ficción moderna han empleado los personajes históricos de doña Marina y Jerónimo Aguilar como personajes ficticios para reinterpretar la historia tradicional formal. Estos autores siguen la tradición cronista de emplear narrativas parciales y subjetivas para reclamar la reputación de los personajes históricos. En las dos novelas analizadas, la identidad bilingüe es fundamental en la reivindicación de la reputación de los personajes que llegan a ser humanos simpáticos, a pesar de sus contribuciones al éxito de la conquista.

\section{PALABRAS CLAVE:}

Biculturalismo | Conquista | Poscolonialismo

This article analyzes how the authors to the modern fiction have used the historical characters of Dona Marina and Jerónimo Aguilar as fictional characters to reinterpret traditional formal history. These authors follow the chronicler tradition of using partial and subjective narratives to claim the reputation of historical characters. In the two novels analyzed, bilingual identity is fundamental in claiming the reputation of the characters who become sympathetic humans, despite their contributions to the success of the conquest.

\section{KEYWORDS:}

Biculturalism | Conquista | Postcolonialism

Este artigo analisa como os autores da fição moderna usaram os personagens históricos de Dona Marina e Jerónimo Aguilar como personagens de ficção para reinterpretar a história formal tradicional. Esses autores seguem a tradição cronista de usar narrativas parciais e subjetivas para reivindicar a reputação dos personagens históricos. Nas duas 
novelas analisados, a identidade bilingue é fundamental na reivindicação da reputação dos personagens que chegam a ser humanos e simpáticos apesar de suas contribuições para o sucesso da conquista.

\section{PALAVRAS CHAVES:}

Bi culturalismo | Conquista | Pós-colonialismo 


\section{Introducción}

Ser bilingüe influye en la identidad de una persona más allá de su capacidad lingüística. Además de que se obtiene otro recurso lingüístico, su uso cambia la perspectiva cultural y pone en conflicto la identidad cultural de las personas. Michael Ignatieff explica: «individuals who are not just bilingual but also bicultural may have distinct frameworks, associated with each of their cultures and languages, that evoke different worldviews and personalities» (1994: 72). Los personajes de las novelas Malinche (Laura Esquivel, publicada en 2006) y Las dos orillas (Carlos Fuentes, publicado en 1993) incorporan identidades y aspiraciones asociadas con las culturas indígena y española, lo cual les permite alejarse moralmente de la matanza y robo que fue la Conquista.

Doña Marina y Jéronimo Aguilar -las figuras históricas- nunca escribieron sus propios recuerdos o sus propias crónicas. Las novelas de Laura Esquivel y de Carlos Fuentes abren paso a un pasado imaginado, pero bien investigado y también citado, simulando a los historiadores modernos. El conocimiento moderno ha llegado a la noción de que la Conquista fue un robo, una matanza, una invasión y un crimen. Mientras los conquistadores escribían crónicas para salvarse políticamente, los autores de estas dos novelas intentan justificar a los personajes históricos por su complicidad en lo que entendemos claramente como crímenes de lesa humanidad.

Antes de todo, los autores los humanizan a los personajes usando técnicas literarias derivadas de los tiempos de los cronistas, narrando desde la primer perspectiva o entrando a la psiquis del personaje. En ambos casos, construyen a los personajes históricos como seres biculturales que, en el caso de Aguilar, traiciona a los españoles para defender su cultura adoptiva; o, en el caso de Doña Marina, solo quiere cambiar los aspectos abusivos de su cultura propia por lo que entiende como una forma de liberación de una cultura adoptiva.

Es por su capacidad como lenguas de la Conquista que los dos personajes llegan a tener un rol clave en la destrucción del imperio azteca, algo de lo que ambos personajes de las novelas se alejan moralmente. Es su capacidad lingüística y, aún más importante, su experiencia como seres biculturales, lo que les permite estos actos de disonancia cognitiva que los humanizan.

No podemos saber qué pensaban o sentían estos seres humanos históricos mientras transcurrieron los eventos centrales de sus vidas y la Conquista. La historiografía de los cronistas, que son las únicas fuentes principales de información que tenemos sobre sus vidas, está llena de parcialidad cultural y personal. Incluso los registros escritos posteriores tampoco son confiables en absoluto. Cada historiador interpreta 
estas fuentes parciales desde su propia perspectiva, informado por su entendimiento cultural y personal. Eso no significa que carezcan de valor ni que estén equivocados, sino que debemos entender y tener en cuenta cómo la realidad histórica ha influido a la historiografía de cada época, incluso a la nuestra. Sin un registro histórico completo y confiable, las vidas, pensamientos y motivos de los dos personajes de la Conquista se abren a especulaciones, conclusiones e interpretaciones motivadas de historiadores y autores de ficción. Es una realidad polémica, que a su vez se convierte en una oportunidad de explorar y entender sus historias de formas que exceden a la historia tradicional.

En sus novelas históricas, Malinche y Las dos orillas, Laura Esquivel y Carlos Fuentes toman esa oportunidad de exploración para narrar la historia de la Conquista desde la perspectiva de cada uno de los protagonistas. En ambas novelas existe una mezcla de historia basada en hechos fácticos y la creación de una narrativa basada en una perspectiva no histórica. Empleando esta mezcla, los autores no rompen con la tradición cronista, sino que la respetan, reconociendo también la falta de credibilidad de los cronistas. Por narrar desde una perspectiva personal, contradictoria y subjetiva, estos autores tratan de recrear o salvar la reputación de las figuras históricas, creando personajes complejos, humanos y simpáticos; algo que fue cercano a los propósitos de muchos cronistas.

En Malinche y Las dos orillas, los personajes ficticios usan a su favor las capacidades lingüísticas que tienen para salir adelante en el marco del inicio de la Conquista que transformó sus tierras natales. Siendo esclavos, su único recurso para salir de ese estatus social fue ser bilingües, aunque esta capacidad también les llegó por ser esclavos. Ambos eran extranjeros dentro de su propia cultura, lo que representaba tener «identidades duales». En las novelas, esa identidad dual afecta cómo actúan y se relacionan con los cambios violentos y destructivos que cursaron mientras vivían y en que ellos mismos tenían papeles formativos.

Este artículo plantea una investigación sobre las novelas, basado en el criticismo moderno. Los autores de las novelas utilizaron las crónicas como fuentes históricas, pero también como inspiración literaria. Después de explicar la base teórica y metodológica del artículo, sigue un análisis del entendimiento moderno de los cronistas como fuentes históricas no confiables, más cercanos a los autores de ficción o a la escritura política y persuasiva. Propongo que el propósito de los autores de las novelas, parecido a los motivos de los cronistas históricos, es crear representaciones ficticias de personajes históricos que son humanizados y simpáticos para así quitarles la culpa de ser cómplices de los actos críminales de la Conquista. 


\section{Marco conceptual y metodología}

El conocimiento y entendimiento moderno de la Conquista están influidos por el poscolonialismo y la estructura jurídica moderna. Los términos de genocidio y crimen contra la humanidad surgieron en el siglo XX, pero han sido aplicados, anacrónicamente, a la colonización de las tierras fuera de Europa. Muertos hace siglos, a los actores históricos de la Conquista, o cualquier otra invasión y anexión de tierra ajena, no se les puede someter al juicio legal. Sin embargo, hoy, la norma social e intelectual es que tomar posesión de tierra ajena es ilegal, así como la represión de creencias, lenguas y culturas.

Las figuras históricas de Doña Marina y Jerónimo de Aguilar nunca dejaron sus propios testimonios de los eventos de la Conquista. Aunque sus capacidades como lenguas los hacían poderosos y conocidos, les faltó la capacidad o el ímpetu de relatar sus perspectivas. Mientras otros actores históricos, tal vez de menos importancia en la empresa, anotaron sus propias perspectivas para protegerse o adelantarse, sobre Doña Marina y de Aguilar solo tenemos testigos de segunda mano.

Es imposible asegurar que estas figuras históricas fueran cómplices del crimen de la Conquista por su propia voluntad, forzados o por una mezcla de avaricia y ambición. Dejando eso al lado, aunque hubieran escrito sus propias crónicas, el entendimiento moderno de las crónicas de la colonización de las Américas nos dejaría con dudas sobre la veracidad de los testimonios. De hecho, es la falta de crónicas propias de los personajes históricos lo que abre paso a la construcción de crónicas ficticias, o sea: novelas. Es la falta de confianza en las crónicas escritas lo que abre el paso a la recreación de lo que es entendido sobre los personajes históricos y sus motivos. Sin una historiografía fija, los autores de las novelas Malinche y Las dos orillas plantean dudas y proponen historias alternas a la historia popular de Doña Marina como traidora y de Aguilar como cualquier otro avaro conquistador.

La reseña bibliográfica que sigue establece que las fuentes principales, las crónicas, representan una historiografía no confiable, la cual es más persuasiva que informativa. Dicho esto, las crónicas mantienen valor tanto de fuentes históricas como literarias en la búsqueda de entendimiento entre las sociedades y conocimientos modernos y el pasado. Los autores de las novelas que son objeto de este estudio, emplean algunas de las técnicas literarias de los cronistas para argumentar una perspectiva política, utilizando la voz de figuras históricas. Elogiando a los cronistas y con base en su estatus como seres biculturales, los autores humanizan a doña Marina y a Aguilar, creando personajes simpáticos, honorables, y, al final, impotentes. 


\section{Historiografía no confiable}

Rolena Adorno explica claramente que «las crónicas de las Indias [...] no solían orientarse por los eventos históricos en sí» (2009: 68). Cada persona puede interpretar, recordar y relatar un evento de una manera diferente $\mathrm{u}$ opuesta a las versiones de otros, incluso cuando cada uno intenta ser neutral e imparcial. En el caso de las crónicas, ser neutral e imparcial, no fue parte del propósito. Cada cronista tenía una agenda personal o política. Hernán Cortés escribía para justificarse ante la monarquía y su corte. Y según Alberto Rivas (1999), el cronista y soldado de Cortés, Bernal Díaz de Castillo escribía para proteger su reputación histórica conforme a su «renacentista deseo de fama» (33).

Otros cronistas, que también vivieron los eventos de la Conquista, no escribían sus relatos «en un espacio incontaminado (ilusorio) de memoria prístina o de especulaciones abstractas», como argumenta Adorno (2009), los narraron mientras sonaba «la cacofonía producida por apasionados debates y discursos» sobre la legalidad y moralidad de la Conquista (70). No estaban fuera de esos debates, sino en medio de ellos. El propósito de los cronistas era más político que histórico, por lo tanto, más persuasivo que informativo.

Es difícil persuadir o crear un legado que dure siglos, solo con datos secos. Los lectores contemporáneos tampoco esperaban una historia imparcial de los cronistas, como explica Adorno: «el peso de la obligación a la fidelidad, al consenso o la verdad, era bastante ligero» (2009: 74). Según Ilse Logie, los expertos modernos en «materia de crónicas de Indias hacen notar [...] que estas, en general, deben más a la imaginación que la descripción real de los hechos» (2005:36). Entonces, no sorprende que entre los cronistas hay muchos datos biográficos, fechas y ubicaciones contradictorias; así, Jerónimo de Aguilar es un «personaje histórico ampliamente documentado, si bien de manera contradictoria» (Logie, 2005: 35). De todas maneras, las crónicas son las únicas fuentes escritas dentro o cerca de la época de la Conquista, y su valor histórico y cultural no desaparece al entender que eran fuentes parciales. De hecho, es su falta de credibilidad y la falta de otros recursos para los estudios históricos, lo que llama la atención.

\section{Fuentes históricas y literarias}

Luis Barjua, autor de La Conquista de la Malinche, un libro histórico sobre la vida de doña Marina, argumenta que «el hecho histórico siempre tiene que estar atenido a la cantidad y calidad de sus testimonios y la calidad de sus interpretaciones» (2009: 
253). Abundan crónicas tituladas con palabras llamativas como «verdadera», «clara», «hechos» $\mathrm{y}$ «historia» que, hoy en día, son reconocidas como «edificantes, exuberantes o entretenidas» (Adorno, 2009: 74). Es notable que los cronistas se citaron entre sí mismos, aumentando la credibilidad del autor anterior solo por citarlo (Rivas, 1999: 32).Los historiadores de la modernidad, por supuesto, elaboran otras perspectivas de las crónicas que las de historiadores contemporáneos.

Hoy se reconoce a los cronistas de las Indias como fuentes imperfectas que tal vez ofrecen más a nivel literario que histórico: «quizá en ninguna otra época de literatura española haya estado tan cerca la historia y la literatura» (Rivas, 1999: 26) como demuestra su uso de «técnicas de la literatura de ficción». Mientras, Adorno argumenta que «es su calidad narrativa más que su supuesta fidelidad a la verdad histórica, la que nos seduce» (2009: 68). Esta interpretación moderna de las crónicas abre una polémica que ella llama «los juegos de espejos en el laberíntico mundo histórico-literario» (77).

La dificultad de ubicarse en este laberinto atrae interpretaciones nuevas que se pretenden como fuentes históricas, ficción, una mezcla de las dos e incluso ejemplos falsificados. El estudio de Persephone Braham (2006) sobre El feliz cautiverio de Gonzalo Guerrero empieza a mostrar un camino dentro del laberinto: es una crónica «fraude que data de los años 1950 o 1960» escrita desde la perspectiva de su protagonista. Existe un acuerdo sobre la falsificación del manuscrito, aunque la mera existencia de Guerrero como persona histórica, es disputada. De todos modos Braham, conforme a lo que escribe Adorno, cuando habla de crónicas auténticas aunque no confiables, argumenta que «la precaria autenticidad de este documento, sin embargo, no reduce a priori su atracción» (2). Entonces, crónicas no confiables y hasta crónicas falsificadas siguen teniendo valor tanto para estudios históricos como literarios y sociológicos. Braham cree que «La existencia de El Relato de Gonzalo Guerrero...responde a un apetito generalizado de cerrar la distancia entre la caótica modernidad y un momento pretérito, reverenciado como seminal en la historia y la identidad mexicana» (4). Por lo tanto, su valor no surge de su credibilidad ni de su autenticidad, sino de necesidades modernas de crear y entender la identidad humana por la historia.

Interpretaciones modernas surgen de esta necesidad humana, sean escritas como historia o ficción. Desde la perspectiva post-estructuralista, como relata Rolando Romero, «history is ultimately a text which differs from fiction only because of the $a$ priori expectation of veracity placed upon the text by both the reader and the writer» (1992: 347). Esta teoría se complica cuando hablamos de la ficción histórica porque las expectativas, tanto para autores como lectores, cambian hasta estar borrosas. Hay diferencia entre verdad y mentira, pero los dos se encuentran en la historia y la ficción. 
«En la historia, la ficción no puede ser un simple sinónimo de la mentira, de la misma manera que el hecho no tiene monopolio de la verdad» (Barjua, 2009: 254). En el caso de los eventos de la Conquista, y particularmente de los sentimientos y perspectivas de figuras históricas que no dejaron sus propias crónicas, es más que probable que Barjua tenga razón cuando declara que «muchas veces ha sido una versión inventada o de ficción más real que la ofrecida por la historia oficial» (254). Desde esta perspectiva, la importancia de un documento, o su interpretación, no deriva de su supuesta veracidad basada en hechos comprobables, sino de su capacidad de expresar una verdad o entendimiento cultural.

Las obras de ficción [...] cuando se han inclinado a la reconstrucción de hechos históricos reales, con un nivel de dominio metódico y temático propio del historiador profesional, han agregado de forma total el sustrato de la imaginación que muchas veces avanza más que la investigación rigurosa del científico social. [...] El hecho sufre la subyugación de las creencias. Y lo ficticio contenido en un mito puede influir poderosamente en la realidad de conjeturas históricas (Barjua, 2009: 254).

No implica que solo la ficción se abre paso dentro del laberinto propuesto por Adorno. Barjua nota que los autores de ficción que obran con la revaluación de la historia, emplean técnicas de investigación de historiadores profesionales. La clave es reconocer cómo la historia y la ficción se influyen entre sí, cómo se completan y hasta cómo se desarrollan en conjunto. Mientras los cronistas emplearon métodos aprendidos de la ficción, son los autores de ficción de hoy quienes utilizan las técnicas de investigación de la historia.

\section{Cronistas modernos}

Malinche y Las dos orillas, desarrollan la búsqueda de entendimiento y conocimiento más profundos de la historia y la humanidad, en el modo que valora Barjua y cuya validez reconocen otros investigadores. Los autores avanzan la historia bajo sus propias intenciones, que no son ajenas a las de los cronistas, aunque muchos siglos los separen de los cronistas. Ellos tienen motivos personales y políticos, la historiografía también juega su parte. Los cronistas disputaban la legalidad y moralidad de la conquista de una tierra lejana y la subyugación de sus pueblos; escribieron para protegerse de ataques motivados política y personalmente. Los autores modernos también escriben sus novelas mientras sonaba una cacofonía, informada por siglos de debates, cambios drásticos en la historiografía y la visión popular de la Conquista. 
Hoy no hay debate sobre la legalidad o la moralidad de la Conquista, sino sobre su importancia histórica y su influencia sobre lo que vino después.

Esquivel y Fuentes narran sus novelas desde las perspectivas de los actores históricos callados. Estas obras entran en la categoría que denominamos «novela histórica posmoderna», que Rosa María Grillo define como: «aquellos textos que re-escriben la Historia, adoptando un punto de vista alternativo y crítico hacia la historiografía oficial» (2007:1). Mientras sus interpretaciones no se conforman a «la historiografía oficial» o tradicional, la perspectiva narradora sí coincide con la de muchos cronistas. Los que observaron y experimentaron la Conquista naturalmente escribían desde la primera persona. Explica Logie (2005), que Fuentes también emplea la primera perspectiva en Los dos orillas, donde «la voz narrativa de Jerónimo de Aguilar nos dirige su monólogo interior desde que murió de peste bubónica» (36). Así también Esquivel emplea el «monólogo interior», aunque no la primera persona. Sin embargo, como describe Jason Youngkeit, «Esquivel nos deja entrar especulativamente en la psique interior de la protagonista» (138). Es un homenaje a los cronistas de quienes dependían los autores, tanto como fuentes de inspiración, como técnica literaria.

\section{La identidad bicultural y simpatía en las novelas}

Los autores entran y hablan desde las psiquis de doña Marina y de Jerónimo de Aguilar, para salvarlos de su existencia de muertos callados, y de ser cómplices activos de la Conquista brutal, como son vistos en la historiografía y en la visión popular moderna. De lejos los dos son nada más que intérpretes, instrumentos, herramientas del conquistador Hernán Cortés para derrotar a Moctezuma, al estado y la nación Azteca. Herramientas del poder invasor y ajeno, que usó sus ventajas tecnológicas y psicológicas para tomar posesión de una tierra y explotar su gente y sus recursos. Tradicionalmente la historia no ha investigado el rol y motivación de Jerónimo de Aguilar ni los de doña Marina. Como náufrago español rescatado por Cortés, su participación en la Conquista parece obvia; como cualquier otro, ayudó en la destrucción de culturas ajenas por ganancias propias. El rol de doña Marina, como indígena, sí ha recibido mucha atención, aunque muy frecuentemente las interpretaciones son negativas. Ella es la Chingada, la violada, la traidora y la puta. En la historiografía tradicional doña Marina, es víctima o villana (Olsson, 2007: 5).

En sus novelas Laura Esquivel y Carlos Fuentes recrean a doña Marina y a Jerónimo de Aguilar como personajes complejos y simpáticos. La simpatía se desarrolla alrededor de sus identidades duales como seres biculturales. Ellos vacilan entre dos estados 
mentales contradictorios. En un momento dado están convencidos de su lealtad a una cultura o la otra, pero unas páginas después están convencidos de lo opuesto.

En Malinche, Malinalli-el nombre indígena de doña Marina, su nombre cristiano-, decide hacerse española tanto como pueda, «tenía que ver las cosas a la manera de los españoles» (Esquivel, 2006:105). Páginas después, «de pronto le parecía que ella y toda su cultura corrían peligro», refiriéndose a la cultura indígena (128). Jerónimo de Aguilar en Las dos orillas (Fuentes, 2005) es también un ser divido. Aunque habla de «mis propios hermanos indígenas», de cómo «me asocié de este modo a la esperanza de una victoria indígena» y en Yucatán «tengo mis verdaderos amigos», usa el pronombre nosotros para referir a los españoles: «nuestro capitán,» «los españoles matamos,» «nos impresionó a los propios españoles». De hecho Aguilar reconoce que sus lealtades están divididas; «tenía también dos patrias; y ésta, quizás, fue mi debilidad más que mi fuerza» (31).

Esta dualidad cultural influye cada aspecto de las vidas de los personajes. Los autores los humanizan para que se vean no como víctimas ni cómplices activos, sino como seres trágicos que intentan hacer bien, aunque fallan. Como explica Sara Olsson: «Esquivel no la muestra como una villana ambiciosa ni mucho menos como una heroína, sino como una mujer de carne y hueso» (2007: 53). La participación activa en lo que hoy serían crímenes de lesa humanidad, es representada como producto de sus deseos de una vida digna; o en el caso de Las dos orillas, el deseo de sabotear la Conquista. Ambos autores humanizan a sus protagonistas exponiéndolos como seres débiles con lealtades divididas. Por sus capacidades lingüísticas, los dos personajes alcanzar poder, solo para perderlo después, siendo rechazados y humillados. De esta forma, pueden llegar a verse a sí mismos como actores impotentes y alejar la culpa de la brutal conquista.

Ni Jerónimo de Aguilar ni doña Marina nacieron en comunidades bilingües español-náhuatl-maya. En las fechas de sus nacimientos estas comunidades no existían, por lo menos no en gran cantidad. Cortés llegó a Yucatán con dos intérpretes indígenas, Julián y Melchorejo (Herrén, 1992: 15). Estos esclavos aprendieron el castellano mientras servían a sus amos, del mismo modo en que doña Marina llegaría a hacerlo. Ella ya era esclava cuando los españoles derrotaron a su amo tabasqueño, quien regaló a doña Marina, junto con otras esclavas suyas, como tributo al capitán español. Jerónimo de Aguilar, también llegó a ser bilingüe bajo el control de otros seres humanos: salvado del sacrificio, ocho años antes de encontrarse con Cortés, el náufrago vivía como esclavo en Yucatán (Braham, 2006: 2).

Estos hechos, históricamente confiables, también están contados en las novelas ficticias. En Malinche doña Marina se dio cuenta de la posibilidad de usar su bilingüismo para adelantarse socialmente mientras aprendía. Cortés se dio cuenta de 
que doña Marina era bilingüe, que hablaba náhuatl, el idioma del imperio azteca, y maya, el idioma que sabía Aguilar. Históricamente, Cortés le ofreció la libertad a cambio de su ayuda en la empresa de la Conquista (Herrén, 1992: 27). En Malinche, Esquivel lo simplifica a «solo el triunfo de los españoles le garantizaba su libertad» (73). Su estatus como esclava y sus esperanzas de salir de la servidumbre y tener una vida digna, sirven para justificar sus actos en servicio de Cortés. Esquivel salva la reputación de Malinalli recreándola como un ser humano que busca una vida mejor, lo que es posible solo por llegar a ser un ser bicultural en tiempos difíciles.

La llegada de los españoles también le ofrece oportunidades al protagonista de Las dos orillas. Jerónimo de Aguilar narra que Cortés «nos prometía a los soldados recompensas al terminar la guerra» (Fuentes, 2005:16). Pero más allá de la libertad, Aguilar busca sabotear la Conquista para proteger la cultura indígena. Como hemos visto, hoy se entiende la Conquista como un acto agresivo e inmoral, entonces, Fuentes intenta salvar la reputación de Aguilar, recreándolo como un traidor a su vieja cultura española y no como un esclavo rescatado.

Lo importante es que estaban asimilándose a culturas ajenas mientras vivían como esclavos. Aprender un idioma y volverse parte de una cultura ajena causa cambios drásticos en el estado mental de cualquier persona de cualquier época. Estas circunstancias traumáticas de esclavitud, entre dos culturas separadas por un océano que chocan, causarían efectos a la psiquis; más allá de lo que es normal contemporáneamente, como aprender por gusto, por trabajo, o por tener refugio. Malinche y Las dos orillas, ofrecen perspectivas sobre este trauma que afectaba a la identidad de los actores históricos. Michael Ignatieff, propone: «By mastering the dominant language by force or will, individuals give testimony to their loyalty to the nation and their motivation to integrate into a community that is based on a particular linguistic identity» (1994: 77). En las novelas, aunque los personajes demuestran lealtad a sus nuevas culturas, no pueden olvidar ni rechazar las viejas; mientras estas estén en guerra y ellos formen parte clave del conflicto.

Aguilar y doña Marina encuentran en Cortés una oportunidad; pero no una relación de dependencia total. Esquivel afirma que «Cortés sabía que no le bastarían los caballos, artillería y los arcabuces para lograr el dominio de aquellas tierras» y que, «sin palabras, sin lengua, sin discurso no habría empresa y sin empresa, no habría Conquista» (42). Y Fuentes, por la boca de Aguilar, argumenta, por otro lado, que fueron «palabras que podían darle más fuerza a Moctezuma que todos los caballos y arcabuces de los españoles» (77). Los dos intérpretes reconocen este poder que tienen y lo gozan. Después de ser esclavos controlados por sus amos, se convierten en seres de máxima importancia, lo que les causa uno de los sentimientos más humanos: el orgullo. En Las dos orillas Jerónimo habla de «mi poder para decidir la paz o la guerra a 
la posesión de las palabras» (Fuentes, 2007:40). Esquivel explica que Malinalli «nunca antes había experimentado la sensación que generaba estar al mando [...] descubrió que al traducir, ella dominaba la situación, y no solo eso, sino que la palabra podía ser una arma» (72). Jerónimo también reconoce a la lengua como arma cuando habla de doña Marina: «Su arma fue la misma que la mía: la lengua» (Fuentes, 2007: 31).

Ese poder surge solamente de sus capacidades lingüísticas, de sus identidades duales, las cuales complican la capacidad de manejar ese mismo poder para sus propósitos. Aunque a Malinche le encanta ser necesitada y valorada por Cortés, no quiere la destrucción completa de su cultura indígena (Esquivel: 72). «Malinalli podía impedir que esto sucediera...pero ella sería asesinada junto a ellos, y no quería morir como esclava» (74). Esquivel usa la migración de las mariposas como símbolo del cambio interno de Malinalli a un ser bicultural, dice que la migración «hace que uno cambie, que se renueve, que sea más fuerte» (106). Ella intenta asimilarse a los españoles con el propósito de encontrar una vida mejor; sin embargo, no es una española, sino un ser bicultural, que no puede ni quiere olvidar o borrar su pasado.

Como traidor a la cultura española, Aguilar intenta usar su poder como agente-doble interpretando el revés de lo que proclama Cortés y se presenta como totalmente aliado a los indígenas: «Todos mis actos, ya lo habéis adivinado y yo os lo puedo decir desde mi sudario intangible, iban dirigidos a esta meta: el triunfo de los indios contra los españoles» (Fuentes: 28). Incluso está orgulloso de su poder: «Con qué alegría recuerdo [...] cuando Cortés dependía totalmente de mí» (39). Sin embargo, su relación con Cortés vacila entre el respeto y el odio, la cual puede representar su relación con su vieja cultura que está destruyendo la nueva. El Aguilar de Fuentes describe el alma de Cortés con una lista de opuestos: una «mezcla deslumbrante de razón y quimera, de voluntad y flaquezas, de escepticismo y de candor fabuloso, de fortuna y mal hado, de gallardía y burlas, de virtud y maldad» (19). El Aguilar de Fuentes es humano y su identidad dual, expresada en su lenguaje, complica sus intentos de presentarse como aliado de los indígenas y enemigo de los españoles. Ilse Logie propone que a pesar de todo lo que proclama, Aguilar no es fiel a su nueva cultura sino que «las memorias de Jerónimo constituyen un ajuste de cuentas por las humillaciones que le fueron infligidas tanto por Cortés como por su rival profesional, La Malinche» (2005:39).

El poder de los personajes resulta transitorio, y al perderlo los sentimientos de orgullo se convierten en impotencia. Esto, de manera brusca, contrasta dolorosamente con la caída de cada uno. Si en su llegada al poder, la Malinalli de Esquivel sentía por Cortés algo como amor envuelto en desconfianza, en la caída solo le quedaba rencor y humillación. Al principio «los ojos de Cortés la desconcertaban: por un lado la atraían y por el otro le daban desconfianza» (Esquivel, 2006: 60). Ella 
vacila entre verlo como un «animal salvaje» $\mathrm{y}$ «la encarnación del venerado dios». Su relación con Cortés, mientras tiene poder, se complica por su doble identidad, que la empuja a respetarlo y quererlo, a la vez que la empuja a verlo como agresor intolerable. Después de ser violada por Cortés, Malinalli «nunca antes se había sentido tan humillada» (127). Cuando ella decide entregarse entera a él, a finales de la novela de Esquivel, él la rechaza «como una loca y estúpida mujer que efectivamente sólo le servía como un objeto, como un instrumento de conquista» (159).

Aguilar, en Las dos orillas, también experimenta sentimientos de amor y rechazo, vinculado a su relación con el poder de ser lengua. Al encontrarse con la Malinche, por primera vez, «la simple vista provoca el placer y la excitación»; Aguilar se enamora no solo de su belleza, sino de la idea de que «juntos podríamos cambiar el curso de las cosas» (Fuentes: 40). Ella lo rechaza, y todo el orgullo y poder se desintegran dejando a un hombre humillado sexual y profesionalmente. «Privado de la hembra deseada, la sustituí por el poder de la lengua. Mas ya habéis visto, hasta eso me lo quitó La Malinche» (44). A cada paso Malinche y Cortés lo sobrepasan, y él acaba odiándose, «por mi inferioridad en las artes del disimulo, la treta y la pausa, en la que excedían mis rivales, Cortés y La Malinche» (27). Malinche le quita todo el poder y la posibilidad de arruinar la campaña de Cortés, «la hembra diabólica lo estaba traduciendo todo [...] la coima del conquistador, me había arrebatado mi singularidad profesional, mi insustituible función» (34). Aguilar termina impotente y fracasado: «mi sexo añoso e incierto bajo el taparrabos, mis viejos zapatos y $\mathrm{mi}$ lengua perdida» (44). La interpretación de Logie no cambia el hecho de que Aguilar se presenta como un fracasado que merece simpatía, tanto por su fracaso personal como por su fracaso histórico en sabotear la Conquista.

Después de tener poder extremo, perderlo y ser rechazados como objetos, cada uno de los personajes puede separarse de las matanzas y destrucciones de la Conquista. Aguilar pregunta: «¿O fueron mis palabras, acaso, un mero trueque y no fui yo sino el intermediario (el traductor) y el resorte de una fatalidad que transformó el engaño en verdad?» (Fuentes 18). Aceptar su impotencia le resulta casi cómodo, como si ya no fuera culpable. Aunque explica sus razones por las cuales escribe, «las posibilidades incumplidas, las alternativas de la libertad, me quitan sueño», y lo suma a una simple frase, «la culpable fue una mujer» (19). El Aguilar de Fuentes, humillado y fracasado, pone toda la culpa de la Conquista violenta y destructiva en los hombros de la Malinche.

Durante los episodios más violentos de Malinche, la protagonista se aleja del poder en momentos justos para justificar su rol en la brutal conquista: «No acababa Malinalli de traducir estas últimas palabras cuando el disparo de un arcabuz dio la señal para que comenzara la carnicería» (Esquivel: 98). Su identidad dual le permite traducir 
las proclamaciones de Cortés que comienzan batallas y después volverse horrorizada a las matanzas en las cuales participó: «Los miles de cadáveres desmembrados, sin vida, sin propósitos tomaron presa el alma de Malinalli» (98). Esquivel presenta a Malinalli como un ser confundido que ejercía su puesto solo para culparse por ser incapaz de evitar la destrucción de la Conquista. Sin embargo, al final, ella se aleja de la culpa porque llega a sentirse incapacitada: «Lo único que tenía claro era que ella no había podido salvar nada» (148). Esquivel la presenta impotente frente a los cambios drásticos, pero no como una cómplice activa en la Conquista, ni tampoco como una víctima sin interés propio. Así Malinalli puede «vomitar sobre Cortés todo su odio», y culparlo por todo el horror que fue la Conquista (182).

\section{Conclusiones}

Las interpretaciones de eventos históricos no son estables. Las memorias fallan y mienten; los motivos cambian. Los testimonios de primera mano no siempre cuentan todo ni saben todo. Hay que tener cuidado con las autobiografías tal vez más que con cualquier otra fuente. Doña Marina y Jerónimo de Aguilar no dejaron crónicas propias, pero seguramente hubieran relatado los eventos de otra manera que en las novelas de Carlos Fuentes y Laura Esquivel. Los autores, sin embargo, dieron voces a los personajes para crear perspectivas humanizadas de ellos que nos llevan al pasado sin perder el contexto de todo lo que ha ocurrido después de la Conquista.

Utilizando técnicas literarias que vienen desde los cronistas del siglo XVII, los autores entran a las psiques de figuras históricas para situarlos dentro del entendimiento poscolonialista de la Conquista y el colonialismo europeo. Sin embargo, más que proponer la posibilidad de que los personajes históricos no era ni traidora ni conquistador avaro, los autores recrean a los personajes como seres humanos de carne y hueso, de aspiraciones y ego frágil. Mientras en la historia tradicional sus capacidades lingüísticas les permitían contribuir a la empresa de la Conquista, las novelas presentan personajes que justifican su complicidad, en parte, por estar entre las dos culturas.

Como todos los humanos, los personajes llegan a preguntarse, de una forma $\mathrm{u}$ otra, «¿quién soy, para qué sirvo?» (Fuentes: 35), como se pregunta Aguilar; o en el caso de Malinalli “¿a quién iba a servir? Y lo más importante: ¿para qué?” (Esquivel: 102). Igual que el resto de la humanidad, esta pregunta no surge en los mejores momentos de sus vidas. De hecho, surge cuando cada uno está en el medio de cambios personales e históricos difíciles. Fueron sus identidades duales y biculturales, lo que 
los llevó a tener un papel histórico, pero, seguramente, fue su humanidad lo que los condujo a esa pregunta, en cualquiera de los idiomas. No existen citas que aseguren que fue así la forma en la que las figuras históricas se plantearon las preguntas; pero no cabe duda de que así lo pensaron, de un modo u otro.

\section{Referencias}

ADORNO, R. (2009). Polémicas Sobre la Posesión de las Indias en las Letras Hispanoamericanas. Taller de Letras, (45): 67-80.

BARJUA, L. (2009). La Conquista de la Malinche. México: MR Ediciones - Instituto Nacional de Antropología e Historia - Conaculta.

BRAHAM, P. (2006). El Feliz Cautiverio de Gonzalo Guerrero. Hispanic Review, 74 (1), 1-17.

ESQUIVEL, L. (2006). Malinche. Madrid: Suma de Letras.

FUENTES, C. (2007). El Naranjo. Buenos Aires: Alfaguara.

GRILLO, R. M. (2007). Francisco del Puerto, Aguilar y Guerrero, tres náufragos entre la palabra y el silencio. América Sin Nombre, (9-10), 98-108.

HERRÉN, R. (1992). Doña Marina, la Malinche. México D.F.: Planeta Mexicana.

IGNATIEFF, M. (1994). Blood and Belonging: Journeys into the New Nationalism. New York: Farrar, Straus and Giroux.

LOGIE, I. (2005). Una Escena de Traducción en América Latina: «Las Dos Orillas» de Carlos Fuentes. Linguistica Antverpiensia NS - Themes in Translation Studies, 4, 35-46.

OLSSON, S. (2007). «La Voz Recuperada de La Malinche: Un Estudio de la Novela Malinche (2006) de Laura Esquivel» (Tesis de la maestría). Stockholm University, Suecia, Stockholm. Recuperado de: http://su.diva-portal.org/smash/record.jsf?pid=diva2\%3A199479\&dswid=-510

RIVAS YANES, A. (1999). Introducción, en Díaz del Castillo, B. Historia Verdadera de la Conquista de Nueva España. Valladolid, España: Castalia Ediciones.

ROMERO, R. J. (1992) Texts, Pre-Texts, Con-Texts: Gonzalo Guerrero in the Chronicles of Indies. Revista de Estudios Hispánicos. 26 (3), 345-67.

YOUNGKEIT, J. (2013). Malinche de Laura Esquivel: una Lucida Revaluación Discursiva de lo Histórico. Confluencia, 28 (2), 136-148. 